\title{
Gamma Irradiation Effects on n-ZnSe/n-Si Isotype Heterojunctions
}

\author{
Indudhar Panduranga Vali ${ }^{1,2} \cdot$ Rashmitha Keshav $^{2} \cdot$ M. Rajeshwari ${ }^{2} \cdot$ K. S. Vaishnavi ${ }^{2}$ - M. G. Mahesha ${ }^{2}$. \\ Pramoda Kumara Shetty ${ }^{2}$ (D)
}

Received: 22 February 2021 / Accepted: 27 September 2021 / Published online: 5 October 2021

(C) The Author(s) 2021

\begin{abstract}
To get an insight into the isotype heterojunction (IHJ) properties, the influence of gamma irradiation (GI) on the structural and electrical properties of $\mathrm{n}-\mathrm{ZnSe} / \mathrm{n}$-Si has been presented. The $\mathrm{ZnSe}$ thin films were deposited onto the $\mathrm{n}$-Si substrate by thermal evaporation technique. The X-ray diffraction (XRD) studies revealed the nanocrystalline nature of ZnSe thin films with prominent (111) orientation. The gamma irradiated samples displayed no crystallographic phase transformation up to $10 \mathrm{kGy}$ irradiation doses. But noticeable and inconsistent modifications in the different lattice parameters were observed due to irradiationinduced effects. From the analysis of I-V characteristics, it has been found a similar trend in the variation of lattice mismatch, Schottky barrier height and interface trap parameter at different irradiation doses. Thus demonstrating the poor rectification properties of n-ZnSe/n-Si IHJs due to intrinsic and gamma-induced defects, and their role in the space charge limited conduction (SCLC) mechanism that significantly dominating over the thermionic emission (TE) mechanism across the barrier.
\end{abstract}

Keywords Isotype heterojunctions · Gamma irradiation · Schottky barrier height · Lattice mismatch · Space charge limited conduction

\section{Introduction}

When two different semiconductors of the same type ( $n-$ or $p$-type ) are brought into close contact, the resulting heterostructure is usually referred to as $n-n$ or $p-p$ isotype heterojunction (IHJ). In $p-n$ junctions, the currents are contributed from both electrons and holes, but in $n-n$ and $p-p$ IHJs, the currents are predominantly contributed from the electrons and holes respectively $[1,2]$. Compared to $p-n$ or Schottky junctions, the current-voltage $(I-V)$ characteristics of IHJs are being fewer reported. In recent years, IHJs is slowly attracting the research community to the fundamental understanding of their properties. Particularly, silicon based IHJs with large lattice mismatch (), for example, In $\mathrm{GaN} / \mathrm{Si}$ ( $17 \%$ ) [2], $\mathrm{Ge} / \mathrm{Si}(4.2 \%$ ) [3] and $\mathrm{ZnO} / \mathrm{Si}(40.1 \%$ ) [4], were being reported to gain insight into the IHJ properties as well as

Pramoda Kumara Shetty

pramod.shetty@manipal.edu

1 Department of Physics, KLE Society's S. Nijalingappa College, Bengaluru 560 010, India

2 Department of Physics, Manipal Institute of Technology, Manipal Academy of Higher Education, 576104 Manipal, India their possible applications, despite experimental difficulties in accounting role of defects due to greater lattice mismatch. Generally, the $p-p$ IHJs are not preferred for high-speed electronic applications due to large effective mass and less mobility of holes [2]. But $n-n$ IHJs have applications in different optoelectronic devices such as solar cells and injection lasers [1], photodetectors [2, 5, 6] and light emitting diodes (LEDs) [7].

From the fundamental and technological point of view, the semiconductor thin film growth on $\mathrm{Si}$ substrate is attractive by considering the possibility of monolithic integration of grown thin film for different applications. Recently, for instance, $Z n$ $O / S i$ heterostructure LEDs have stirred up considerable interest in integrating $\mathrm{ZnO}$ onto $\mathrm{Si}$ technology [2, 4, 6, 7]. Among the zinc chalcogenide family, $\mathrm{ZnSe}$ possess quite interesting properties, particularly, its direct wide bandgap $(2.7 \mathrm{eV})$ and intrinsic $n$-type conductivity which offers several applications in the field of optoelectronics, such as blue LEDs and lasers [8], thin film solar cells [9], second harmonic generation [10] and nonlinear switching [11]. Despite considerable interest, very few reports are available on the electrical properties of $\mathrm{ZnSe}$ based heterojunctions. In particular, understanding $Z$ $n \mathrm{Se} / \mathrm{Si}$ heterojunctions are essential for integrating $\mathrm{ZnSe}$ onto $S i$ technology. In this view, the present study deals with the 
fundamental understanding of $n-Z n S e / n-S i$ IHJs by accounting junction $I-V$ characteristics. In addition, to have an insight into junction properties such as lattice mismatch, interface defects and Schottky barrier height, we have deliberately introduced defects by gamma irradiation. The consequent effects are outlined in the paper.

Usually, irradiation studies are carried out to account for the nature of intrinsic defects as well as irradiation-induced defects in the materials. However, the defects can be induced only if the incident radiation energy is greater than the displacement threshold energy $\left(E_{D}\right)$ of constituting atoms in the material. The displacement threshold energies for $\mathrm{Zn}$ and $\mathrm{Se}$ atoms are about 10 and $8.2 \mathrm{eV}$ respectively [12]. The electron, gamma, neutron and swift heavy ion irradiation are the most widely used techniques to introduce defects in the material. These irradiation studies are therefore not only useful in the fundamental understanding of the defect dynamics but also give insight into the material behaviour in the radiation environments. In the present study, prepared $n-\mathrm{ZnSe} / n-\mathrm{Si}$ IHJs have been subjected to $C o-60$ gamma irradiation at different irradiation doses (up to $10 k G y$ ) to account for irradiation induced modifications in the junction properties. Efforts were made to correlate the structural parameters with junction parameters and the underlying role of defects on the junction $I-V$ characteristics are presented in detail.

\section{Materials and Methods}

Phosphorus doped $S i$ wafer $(n-S i)$ having a doping concentration of $1.5 \times 10^{15} \mathrm{~cm}^{-3}$ was procured from Sigma Aldrich, India. The wafer thickness was $500 \mu \mathrm{m}$, diced into dimensions of $0.5 \times 0.5 \mathrm{~cm}$ and cleaned according to the standard procedures [13]. The high purity ZnSe compound of $99.999 \%$ was then deposited onto cleaned and diced $n-S i$ by thermal evaporation technique. The deposition was carried out at the rate of $2 \overline{\mathrm{A}} / \mathrm{s}$. A base pressure of $8 \times 10^{-6} \mathrm{mbar}$ was maintained during deposition. The thickness of the $\mathrm{ZnSe}$ thin film was kept at $100 \mathrm{~nm}$ by monitoring the quartz crystal [14].

The prepared $n-\mathrm{ZnSe} / n-\mathrm{Si}$ heterojunctions were subjected to gamma irradiation (GI) using Co - 60 source at Centre for Applications for Radioisotope and Radiation Technology (CARRT), Mangalore University, India. The Co -60 source emits the photons of two energies, 1.17 and 1.33 $\mathrm{MeV}$, which is well above the displacement threshold energies of $\mathrm{ZnSe}$ [12]. The dose rate of the Co - 60 gamma source during irradiation was $2.6 k G y / h r$. The samples were exposed to the different GI doses in the range of $2-10 k G y(2,4,6,8$ and 10). The X-ray diffraction (XRD) studies were carried out using Rigaku Miniflex-600 diffractometer $(C u-k \alpha: 0$. $15402 \mathrm{~nm}$ ). The junction $I-V$ characteristics were taken using Keithley source meter 2450 at room temperature and under dark conditions. The aluminum pressure contacts were used as ohmic contacts during the measurements.

\section{Results and Discussion}

\subsection{XRD Analysis}

Figure 1 shows the XRD pattern of $\mathrm{ZnSe}$ thin film deposited on $n-S i$ substrate before and after GI. The peak at about $27^{0}($ $2 \theta$-value) is attributed to reflection from (111) plane of cubic phase $\mathrm{ZnSe}$. This result is consistent with various reports of thermally evaporated $\mathrm{ZnSe}$ thin films having prominent (111) orientations [14-20]. No peaks from the hexagonal phase of $\mathrm{ZnSe}$ were noticed in the present study before and after GI, suggesting no crystallographic phase transformations. The lattice parameter of $\mathrm{ZnSe}$ has been evaluated from the prominent (111) peak by using the following simplified expression,

$a_{\text {ZnSe }}=\frac{\sqrt{3}}{2} \frac{\lambda}{\sin \theta}$

On the other hand, the XRD peak noticed at $69.2^{\circ}(2 \theta-$ value) has been attributed to the prominent (400) reflection from $n-S i$ substrate. This peak is also consistent with various reports [13]. The lattice parameter of $n-S i$ is evaluated by using the following simplified expression [13],

$a_{S i}=\frac{2 \lambda}{\sin \theta}$

where $\theta$ is Bragg's angle and $\lambda=0.15402 \mathrm{~nm}$ (wavelength of $C u-k \alpha)$. The other important deposited $\mathrm{ZnSe}$ thin film parameters such as crystallite size $(D)$, lattice strain $(\epsilon)$, dislocation density $(\delta)$ and lattice mismatch $(\Delta[21])$ were calculated by using the following relations [14-20]:

$\mathrm{D}=\frac{0.94 \lambda}{\beta \cos \theta}$

$\varepsilon=\left[\frac{\lambda}{\mathrm{D} \cos \theta}-\beta\right] \times \frac{1}{\tan \theta}$

$\delta=\frac{15 \varepsilon}{a \mathrm{D}}$

$\Delta=\frac{a_{Z n S e}-a_{S i}}{a_{Z n S e}}$

where $\beta$ is the full width at half maximum in radians. The evaluated values from Eqs. (1-6) are reported in Table 1.

In the present study, the $a$ value of $Z n S e$ deposited on $n-S i$ substrate was found to be $0.5693 \mathrm{~nm}$. But lesser values have been reported for $\mathrm{ZnSe}$ thin films deposited on glass substrates $(0.563 \mathrm{~nm}[15] 0.5637 \mathrm{~nm}$ [20], and $p-S i$ substrate $(0.5681 \mathrm{~nm}$ [17]). These results suggest that $\mathrm{ZnSe}$ deposited on $n-\mathrm{Si}$ substrate has comparatively a greater value of $a$. Also, these 

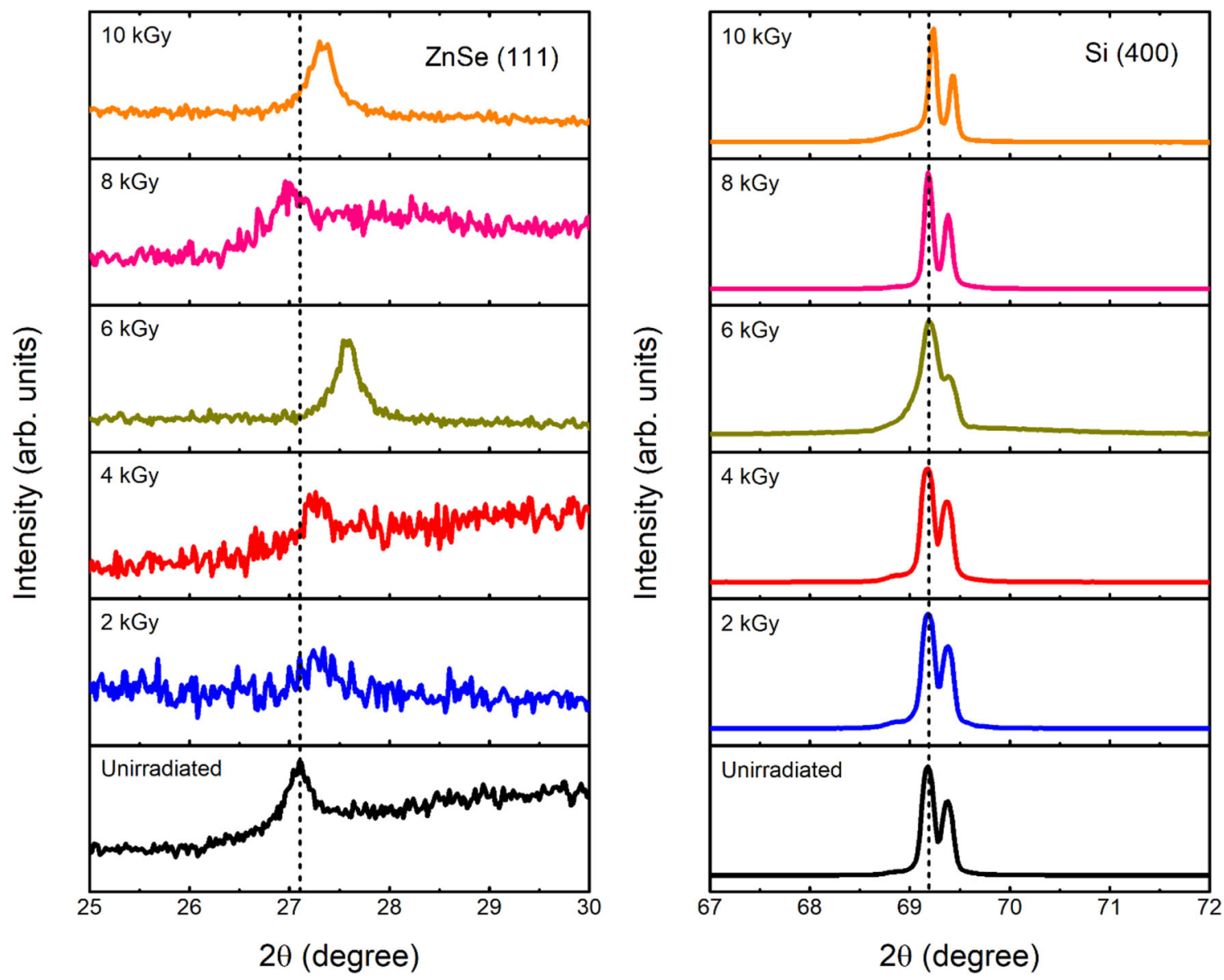

Fig. 1 (111) reflection of $\mathrm{ZnSe}$ thin films on $n-S i$ substrate before and after gamma irradiation

marginal variations in $a$ of $Z n S e$ suggesting the role of $n$ $-S i$ substrate in increasing $D$ and reducing $\epsilon$ and $\delta$ of the deposited thin film. ZnSe deposited on the glass substrate have $D, \epsilon$ and $\delta$ values of $19 \mathrm{~nm}, 2.057 \times 10^{-3}$ and 2.912 $\times 10^{15} \mathrm{~m}^{-2}$ [20] respectively. While for $\mathrm{ZnSe}$ deposited on $p-S i$ substrate have $a, D, \varepsilon$ and $\delta$ values of $0.5681 \mathrm{~nm}$, $40.71 \mathrm{~nm}, 9.5 \times 10^{-4}$ and $6.03 \times 10^{15} \mathrm{~m}^{-2}$ respectively [17]. The latter values are similar to the present study (Table 1). However, an order of lesser values of $\delta$ in the present study suggests better quality of $\mathrm{ZnSe}$ thin films deposited the on $n-S i$ substrate.
As noticed from Fig. 1, the gamma irradiated samples have exhibited no uniformity in the trend of (111) peak of ZnSe with the increase of GI dose. However, from Fig. 2, one can notice an inverse trade-off between $D$ and $\varepsilon$ as a function of GI dose. A similar trend has been also observed between $D$ and $\delta$, as the variation of $\varepsilon$ and $\delta$ are similar because of Eqs. (4) and (5) respectively. However, no such trend has been noticed for variation in $a$ of $\mathrm{ZnSe}$ for an increase in GI dose. These observations suggesting the complex nature of GI induced structural modifications in the $n-\mathrm{ZnSe} / n-\mathrm{Si}$ heterojunction properties. A similar inconsistent variation in $a$ has been also reported for gamma irradiated $A l / n-S i$ Schottky junctions [13].
Table 1 Lattice parameters of $Z n$ Se thin film deposited on $n-S i$ substrate before and after gamma irradiation

\begin{tabular}{lllllll}
\hline Sample & $a(\mathrm{~nm})[\mathrm{ZnSe}]$ & $\mathrm{D}(\mathrm{nm})$ & $\varepsilon \times 10^{-4}$ & $\delta \times 10^{14} \mathrm{~m}^{-2}$ & $a(\mathrm{~nm})[\mathrm{Si}]$ & $\Delta(\%)$ \\
\hline Unirradiated & 0.5693 & 59.6 & 6.56 & 2.89 & 0.5426 & 4.69 \\
$2 \mathrm{kGy}$ & 0.5652 & 41.7 & 9.25 & 5.89 & 0.5426 & 3.99 \\
$4 \mathrm{kGy}$ & 0.5656 & 71.5 & 5.47 & 2.02 & 0.5426 & 4.06 \\
$6 \mathrm{kGy}$ & 0.5596 & 52.3 & 7.39 & 3.79 & 0.5425 & 3.06 \\
$8 \mathrm{kGy}$ & 0.5710 & 29.1 & 13.61 & 12.28 & 0.5426 & 4.97 \\
$10 \mathrm{kGy}$ & 0.5648 & 53.9 & 7.29 & 3.53 & 0.5423 & 3.98 \\
\hline
\end{tabular}


3.2 Analysis of $I-V$ Characteristics by Thermionic Emission Theory

Figure 3 shows the $I-V$ characteristics of $n-Z n S e / n-S i$ IHJs before and after gamma irradiation. One can notice rectifying (Schottky) nature of the heterojunctions rather than ohmic type. However, the rectification ratios (rectification ratio, $\mathrm{RR}=$ forward current/reverse current) are small compared to that of Schottky or $p n$ diodes. The rectifying nature suggests that there exists a potential barrier that must be overcome by the charge carriers (electrons) across the $n-n$ heterojunction. As $Z n$ is metal and $S e$ is metalloid, and the $I-V$ characteristics are mainly governed by electrons, the $n-n$ heterojunction properties in the present study can be accounted by applying thermionic emission (TE) theory of Schottky junctions.

According to TE theory, the forward current $I$ across the junction for the applied voltage $V$ is given by [22],

$I=I_{S} \exp \left(\frac{\mathrm{qV}}{\eta \mathrm{kT}}\right)\left\{1-\exp \left(-\frac{\mathrm{qV}}{\mathrm{kT}}\right)\right\}$

where,

$I_{s}=A A^{* *} T^{2} \exp \left(-\frac{\mathrm{q} \Phi_{\mathrm{B} 0}}{\mathrm{kT}}\right)$

known as reverse saturation current, $q$ is electronic charge, $k$ is Boltzmann constant, $T$ is absolute temperature, $\eta$ is ideality factor, $A$ is device area $\left(\sim 0.25 \mathrm{~cm}^{2}\right), A * *$ is Richardson constant (for $n$-, $S i, A^{* *}=112 \mathrm{~A} \cdot \mathrm{cm}^{-2} K^{-2}[13,22]$ ) and $\Phi_{\mathrm{B} 0}$ is zero-bias Schottky barrier height.

From Eq. (7), it follows that the plot of $\ln (\mathrm{I} /\{1-\exp (-q V / k T)\})$ against $V$ gives a straight line even for values of $V$ [22]. Thus, from the intercept and slope of the plot, one can determine $\Phi_{\mathrm{B} 0}$ and $\eta$ respectively by using the following relations:

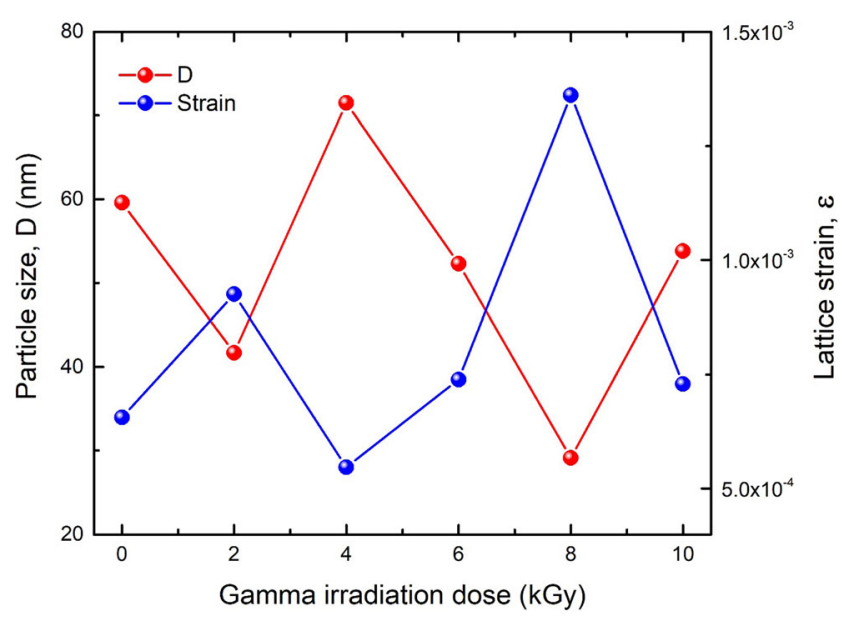

Fig. 2 Variation of particle size $(D)$ and lattice strain $(\varepsilon)$ of $\mathrm{ZnSe}$ deposited on $n-S i$ substrate before and after gamma irradiation

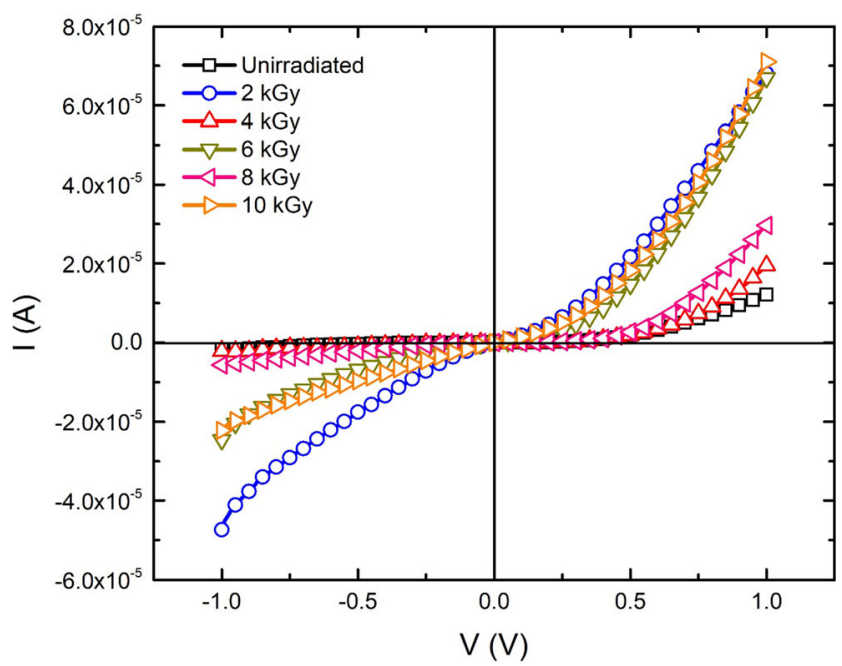

Fig. $3 I-V$ characteristics of $n-Z n S e / n-S i$ IHJs before and after gamma irradiation

$\Phi_{B 0}=\frac{k T}{q} \ln \left[\frac{\mathrm{AA}^{* *} \mathrm{~T}^{2}}{\mathrm{I}_{\mathrm{s}}}\right]$

and

$\eta=\frac{q}{k T} \frac{d V}{d \ln (\mathrm{I} /\{1-\exp (-\mathrm{qV} / \mathrm{kT})\}}$

The straight line fits of the plots of $\ln$ $(\mathrm{I} /\{1-\exp (-\mathrm{qV} / \mathrm{kT})\})$ vs. $V$ at lower voltage regions are given in Fig. 4 and the obtained values of $\Phi_{B 0}$ and $\eta$ from these plots are reported in Table 2.

However, $\Phi_{B 0}$ and $\eta$ values obtained from the TE theory (Eq. (7)) sometimes leads to an erroneous determination due to non-consideration of series resistance $\left(R_{S}\right)$ in the evaluation procedure. The $R_{S}$ is mainly presented from the heterojunction structure (bulk and interface) and ohmic contact regions. Therefore, by considering the effect of $R_{S}$ in the evaluation procedure, one can obtain more reliable values of $\Phi_{B 0}$ and $\eta$. In literature there exist different approaches to evaluate $\Phi_{B 0}$ and $\eta$ after the consideration of $R_{S}$ in Eq. (7). In the present study, we applied the graphical method proposed by Cheung and Cheung, also known as the Cheung model [23]. The brief outline of the evaluation procedure is as follows:

The TE model Eq. (7), for the applied voltage $V>3 k T / q$ takes the form as:

$I=I_{s} \exp \left[\frac{q\left(V-I R_{s}\right)}{\eta k T}\right]$

The differentiation of Eq. (11) for $I$ gives the relation,

$\frac{d V}{d(\ln I)}=R_{s} I+\frac{\eta k T}{q}$ 

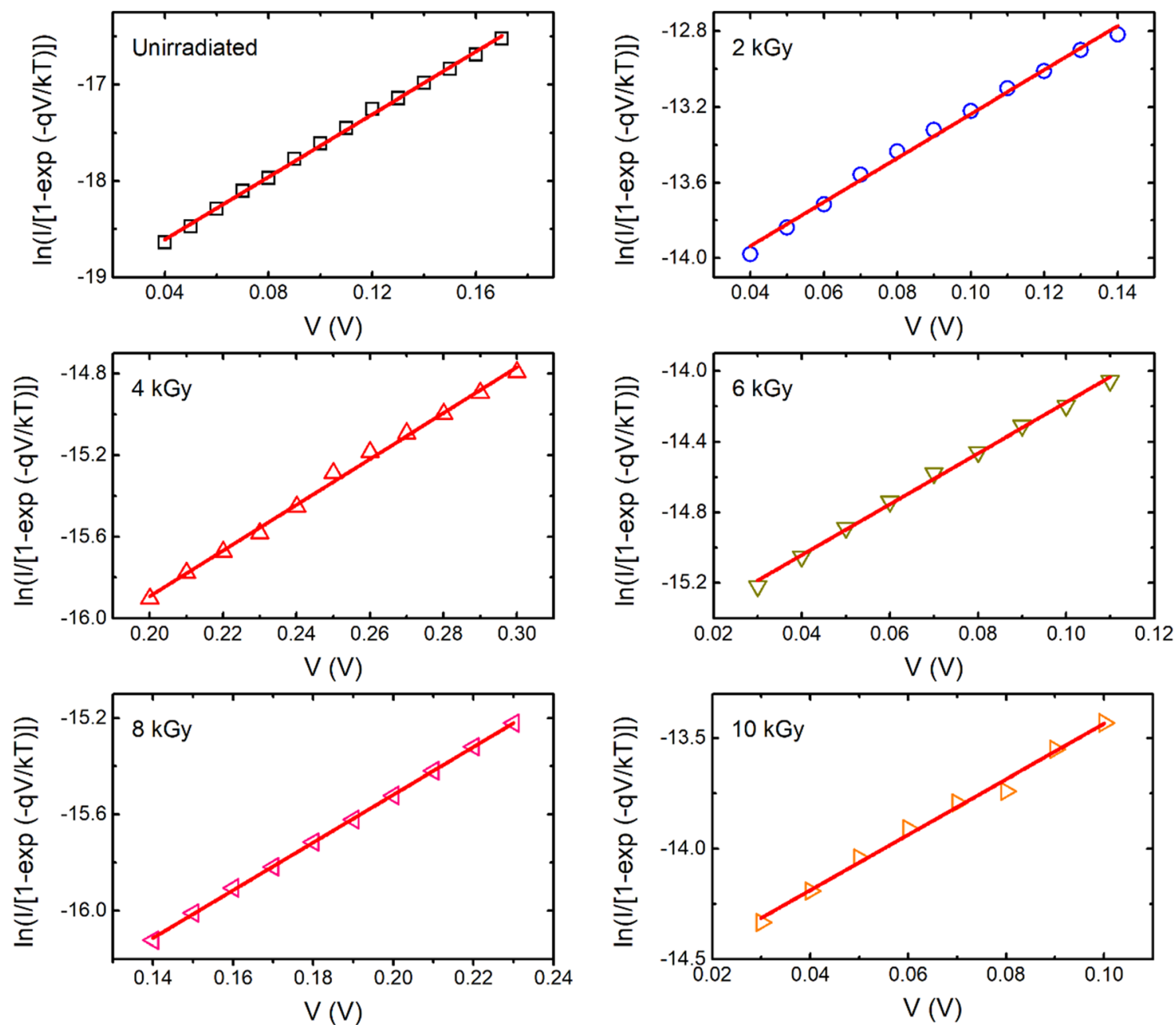

Fig. $4 \ln (I /\{1-\exp (-q V / k T)\})$ vs. $V$ plots of $n-Z n S e / n-S i$ IHJs before and after gamma irradiation

Therefore, the slope and intercept of the $\frac{d V}{d(\operatorname{lnI})} v s . I$ plot gives $R_{S}$ and $\eta$ respectively. On the other hand, $\Phi_{B 0}$ can be determined by plotting the $H(I) v s . I$ such that

$H(I)=R_{S} I+\eta \Phi_{B 0}$

Table $2 n-\mathrm{ZnSe} / n-\mathrm{Si}$ IHJ parameters before and after gamma irradiation at different doses

\begin{tabular}{llllllr}
\hline$n$-ZnSe $/ n$-Si & \multicolumn{2}{l}{ TE Model } & & \multicolumn{2}{l}{ Cheung's Model } \\
\cline { 2 - 3 } \cline { 7 - 8 } & $\eta$ & $\Phi_{\boldsymbol{B} 0}$ & & $\eta$ & $\Phi_{\boldsymbol{B} 0}$ & $\mathbf{R}_{\mathbf{s}} \boldsymbol{k} \Omega$ \\
\hline Unirradiated & 2.38 & 0.88 & & 2.28 & 0.88 & 175.8 \\
$2 \mathrm{kGy}$ & 3.32 & 0.75 & & 2.29 & 0.75 & 15.3 \\
$4 \mathrm{kGy}$ & 3.44 & 0.86 & & 2.40 & 0.88 & 76.7 \\
$6 \mathrm{kGy}$ & 2.68 & 0.79 & & 1.90 & 0.79 & 33.2 \\
$8 \mathrm{kGy}$ & 3.90 & 0.83 & & 3.77 & 0.83 & 32.1 \\
$10 \mathrm{kGy}$ & 3.07 & 0.76 & & 2.85 & 0.76 & 16.1 \\
\hline
\end{tabular}

where

$H(I)=V-\frac{\eta k T}{q} \ln \left(\frac{I}{A A^{* *} T^{2}}\right)$

As the effect of $R_{S}$ is significant in the downward curvature region of the $I-V$ characteristics (Fig. 3), it is therefore customary to select the downward $I-V$ curvature region in the evaluation of $\Phi_{B 0}, \eta$ and $R_{S}$ from the Eqs. (12) and (13). Also, $\eta$ value obtained from Eq. (12) plots must be taken under consideration in the evaluation of $H(I)$ and $\Phi_{B 0}[13,22,24]$. The selected downward curvature voltage regions for the unirradiated, 2, 4, 6, 8 and $10 k G y$ gamma irradiated samples lie in the range of $0.14-0.25,0.12-0.25,0.32-0.39,0.15-0$ $.20,0.20-0.35$ and $0.10-0.25 \mathrm{~V}$ respectively. The respective Cheung plots are shown in Figs. 5 and 6 and obtained junction parameters from these plots are reported in Table 2.

From Table 2, one can notice discrepancies in the values of $\Phi_{B 0}$ and $\eta$ evaluated from the TE and Cheung model due to 
non-consideration of $R_{S}$ in TE theory Eq. (7). The $\Phi_{B 0}$ of the unirradiated $n-\mathrm{ZnSe} / n-\mathrm{Si}$ IHJ in the present study was found to be $0.88 \mathrm{eV}$ with $\eta$ value of 2.28. Previously, Rashmitha et al. [14], Hassun et al. [25] and Güzeldir et al. [26] have reported $\Phi_{B 0}(\eta)$ values of 0.957 (1.756 ), 0.825 ( 2.157 ) and $0.779 e \mathrm{~V}(1.217)$ respectively. It is also interesting to note that for $n-\mathrm{ZnSe} / p-\mathrm{Si}$ heterojunctions, the reported $\Phi_{B 0}(\eta)$ values are 0.832 (2.910) [18] and $0.78 e V(3.2)$ [16]. Given these values, it is evident that the overall variation of $\Phi_{B 0}$ lies approximately in the range of $\pm 0.1 \mathrm{eV}$ for the present study value of $0.88 \mathrm{eV}$. These observations suggest that the $\Phi_{B 0}$ dependence on the type of $S i$ substrate is rather minimal but depends on the degree of homogeneity of the junction $(\eta)$ owing to differences in the processing conditions (defects) as well as lattice mismatch (Tables 1 and 2).

Similar to XRD studies, no uniform trend in the variation of junction parameters was noticed in the gamma irradiated $n$ $-\mathrm{ZnSe} / n-\mathrm{Si}$ IHJs. However, as noticed from Fig. 7, the
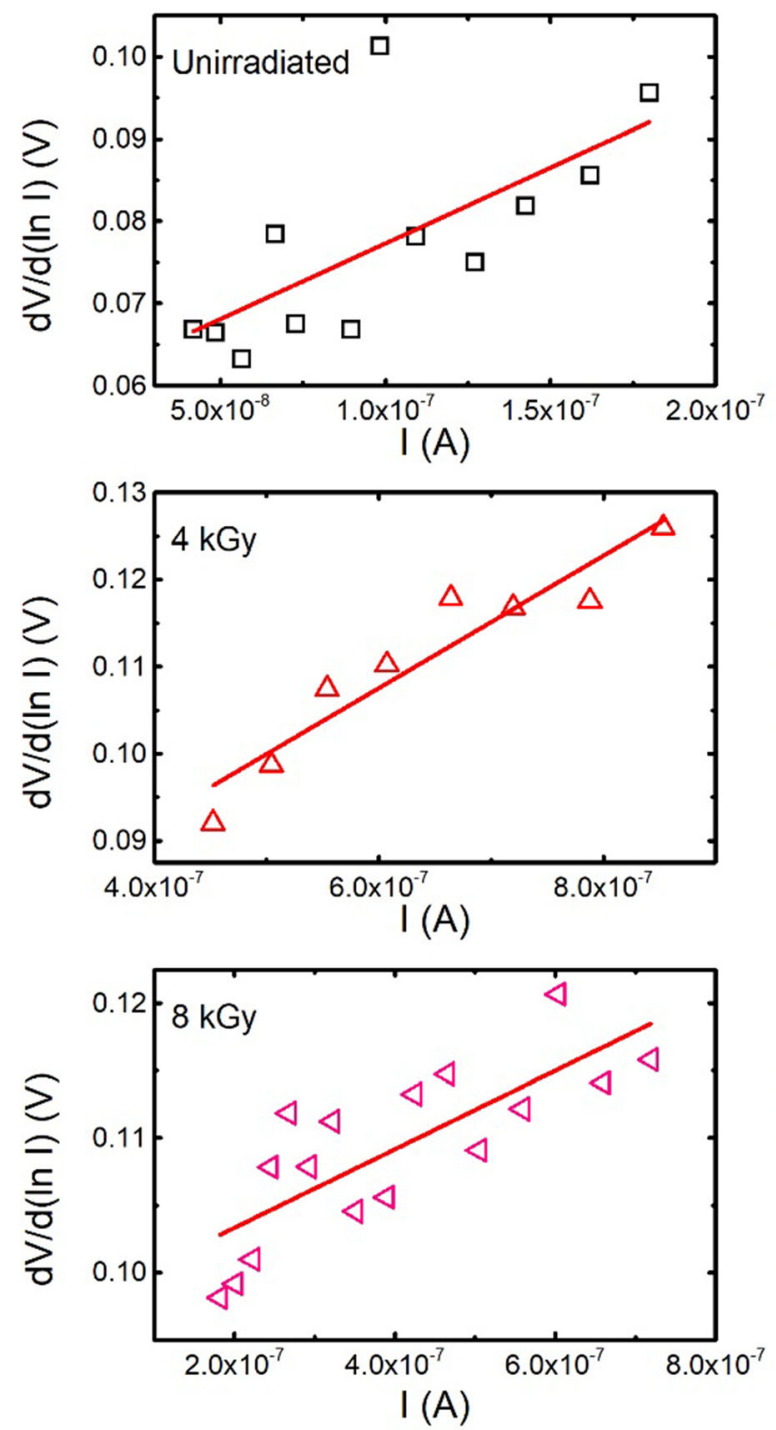

parameters, such as RR, $R_{S}, \Phi_{B 0}$ and displaying identical trends in their variation at different GI doses. This demonstrates the direct correlation among these parameters for GI dose. However, $\eta$ (not shown) has displayed a similar trend only for the GI doses in the range of $6-10 k G y$ while deviated at 2 and $4 k G y$ GI doses. This discrepancy shows the complex nature of GI induced structural modifications in the bulk and interface properties of $n-\mathrm{ZnSe} / n-\mathrm{Si}$ heterojunctions. Similar irregularity in trends was reported in $\mathrm{Al} / \mathrm{n}-\mathrm{Si}$ Schottky junctions due to gamma induced structural modifications by generating defects [13].

\subsection{Analysis of Power Law $I-V$ Characteristics}

From the above as well as reported studies, $\eta>1$ suggests the inhomogeneous nature of the junction or simply, Schottky barrier height $(\mathrm{SBH})$ inhomogeneity. The greater the value
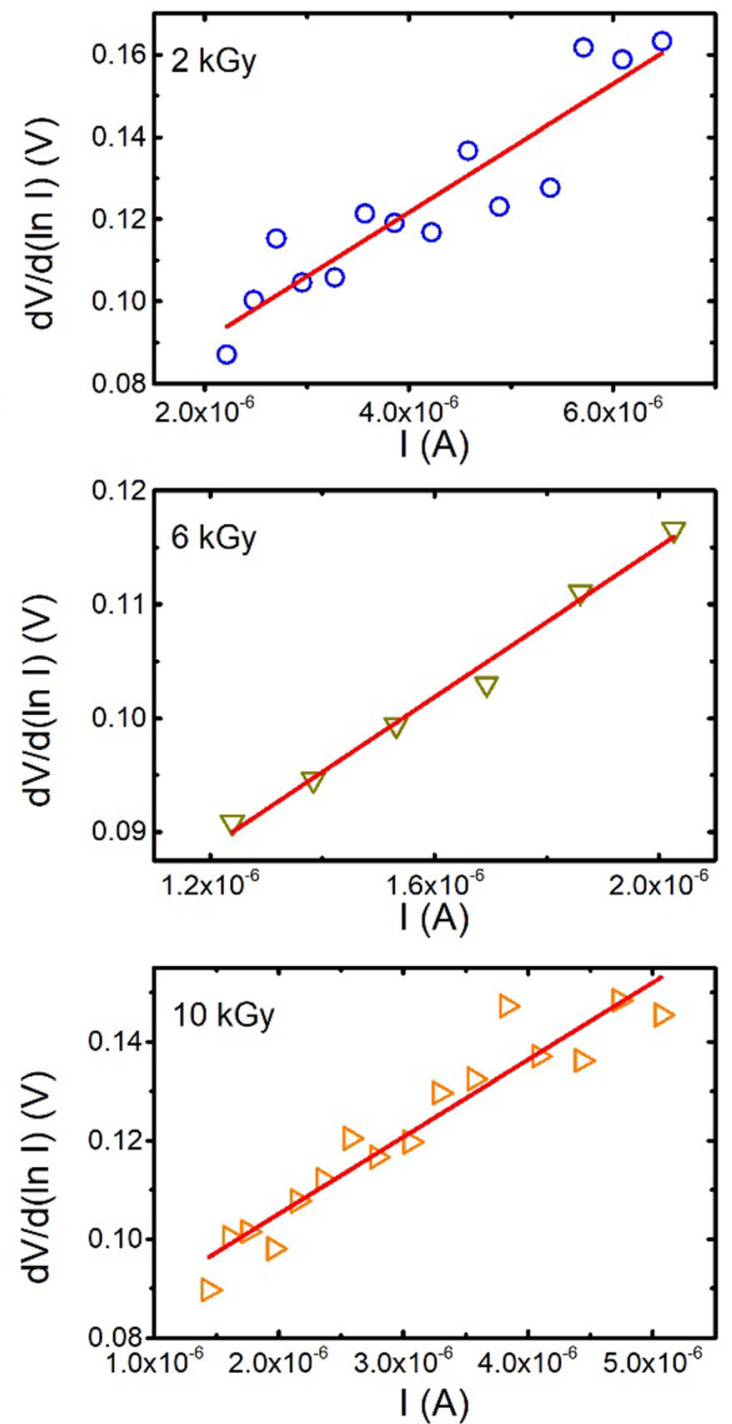

Fig. $5 d V / d(\ln I) v s . I$ plots of $n-Z n S e / n-S i$ IHJs before and after gamma irradiation 

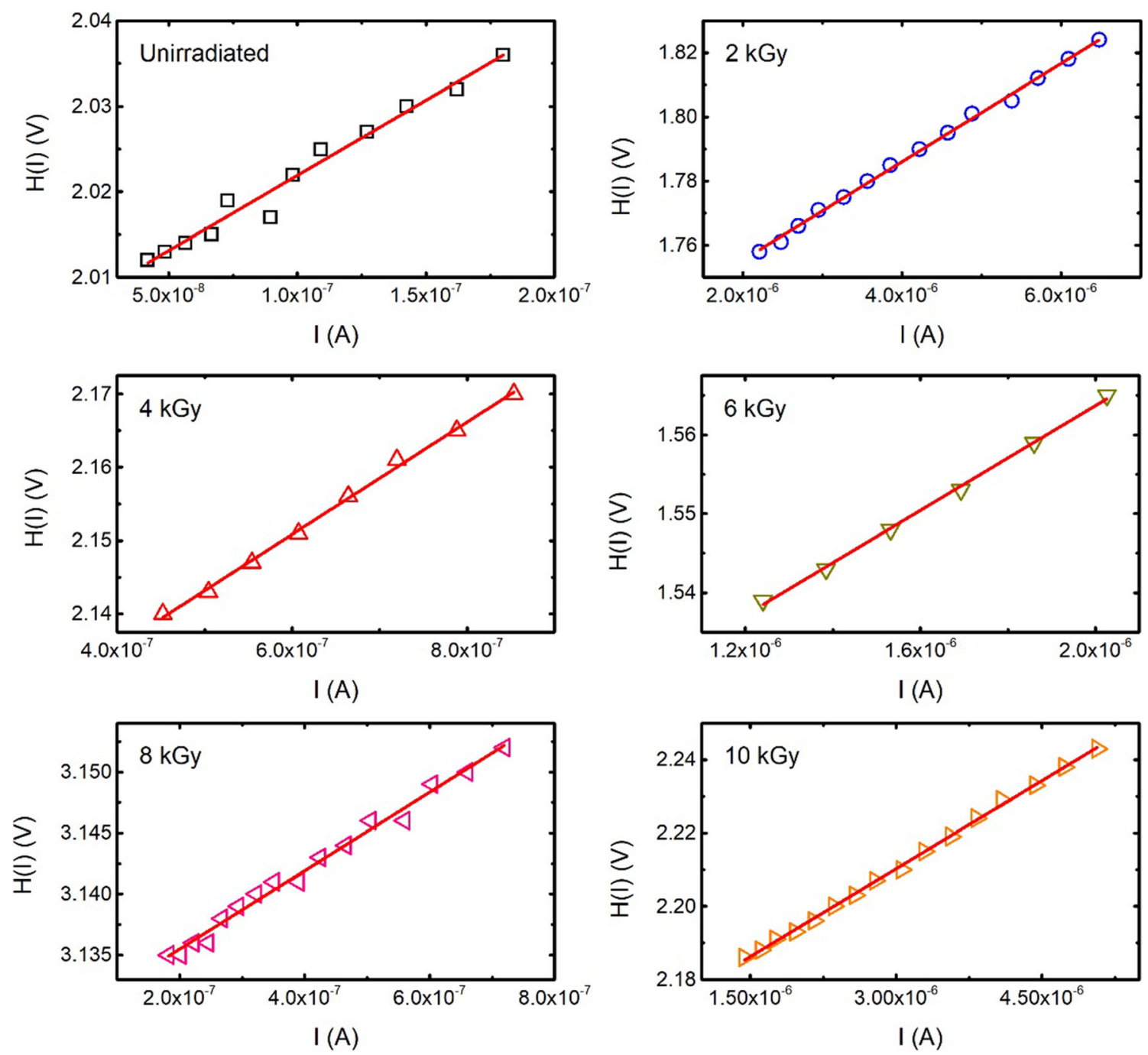

Fig. $6 H(I) v s . I$ plots of $n-Z n S e / n-S i$ IHJs before and after gamma irradiation

of $\eta$, the greater is the SBH inhomogeneity. This inhomogeneity is mainly attributed to the role of defects, either processed or irradiation induced [13, 24, 27]. Tung [28] also pointed out that the electrical data from polycrystalline Schottky barriers have always shown clear signs of SBH inhomogeneity. This is reasonable, since TE model Eqs. (7) and (11) are based on the assumptions that SBH is homogeneous when $\eta$ $=1$ (free of defects) and $R_{s}$ is independent of bias respectively. But the fact is, most practical junctions exhibit SBH inhomogeneity due to the role of defects or the presence of an interfacial layer. Due to this, one can always notice bias dependence i.e., $\eta>1$ and considerable value of $R_{s}$ [27-29]. Also, the $I-V$ characteristics of the junctions should be highly asymmetric (rectifying) if dominated by SBH (or thermionic emission, TE). However, the $I-V$ characteristics shown in Fig. 3 are not highly asymmetric (poor rectification ratio), suggesting that the charge transport is not only controlled by the TE process but also the participation of defects/interface trap states in the transport mechanism across the junction. In other words, the departure of $\eta$ from unity can be attributed to the presence of interface trap states and their participation in another transport mechanism(s) in addition to the TE process. In this view, it is necessary to account for the role of interface trap states on the $I-V$ characteristics of $n-\mathrm{ZnSe} / n-\mathrm{Si}$ IHJs before and after GI.

Apart from the tunneling process (which usually occurs for the devices with high dopant concentration or trap states), the space charge limited current (SCLC) is a widely studied conduction mechanism in single carrier devices like Schottky or heterojunctions or organic material junctions. It is common to plot SCLC $I-V$ profiles on a double logarithmic scale to monitor current regimes by considering the slope, $m$, of the $I$ $V$ characteristics on a log-log scale [29], i.e.,

$m=\frac{d \log \mathrm{J}}{d \log \mathrm{V}}$ or $\mathrm{J} \propto \mathrm{V}^{\mathrm{m}}$

Figure 8(a) shows $\log \mathrm{I}-\log \mathrm{V}$ plots of $n-\mathrm{ZnSe} / n-\mathrm{Si}$ IHJs before and after GI. Strikingly, all the samples have 
Fig. 7 Variation of Schottky barrier height $\left(\Phi_{B 0}\right)$, series resistance $\left(\mathrm{R}_{s}\right)$, lattice mismatch ( ) and rectification ratio $(R R)$ of $n$ $-\mathrm{ZnSe} / n-\mathrm{Si}$ IHJs before and after gamma irradiation
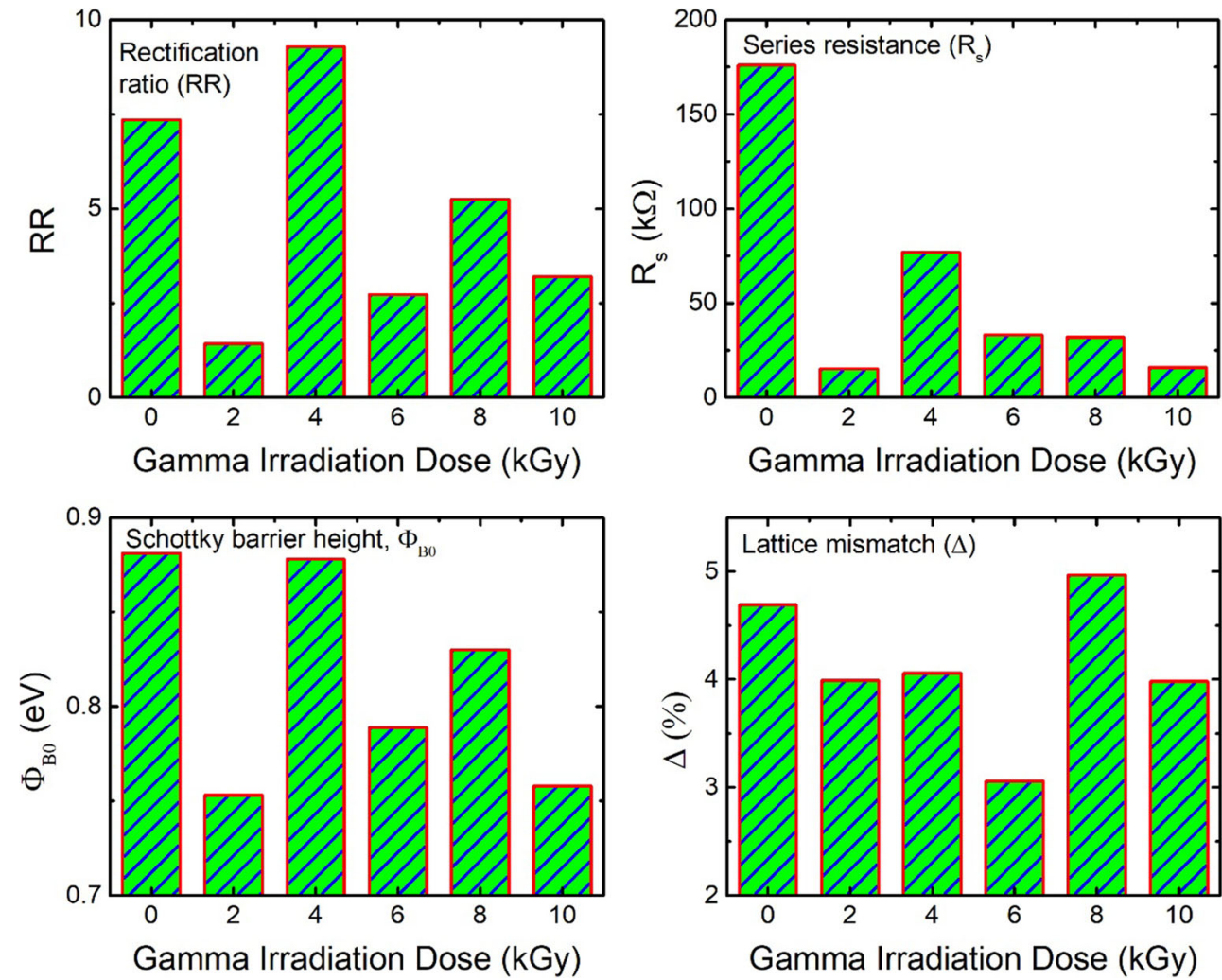

exhibited two different regions of slope $m$ values. Usually, $m$ $=1$ and $m=2$ in Regions I and II, are attributed to the ohmic and SCLC conduction mechanisms respectively [29]. As noticed, in Region I, the unirradiated sample has a $m$ value of 1 .44 which is substantially greater than unity, while that of for irradiated ones (except at 2 and $4 k G y$ GI dose) $m$ values are nearly equal to unity, indicating the ohmic type of conduction mechanism. In Region II, $m=2$ has not been observed in our studies and therefore cannot be accounted by the ideal MottGurney law of SCLC [29]. This deviation of $m=2$ in Region II as well as neither $m=1$ or 2 in Region I for the unirradiated samples are the clear consequences of SCLC modulated by interface defect states. For this reason, the shape of the $I-V$ characteristics is not only controlled by the SBH (TE) but also strongly depends on the distribution of interface trap states and their participation in the SCLC mechanism.
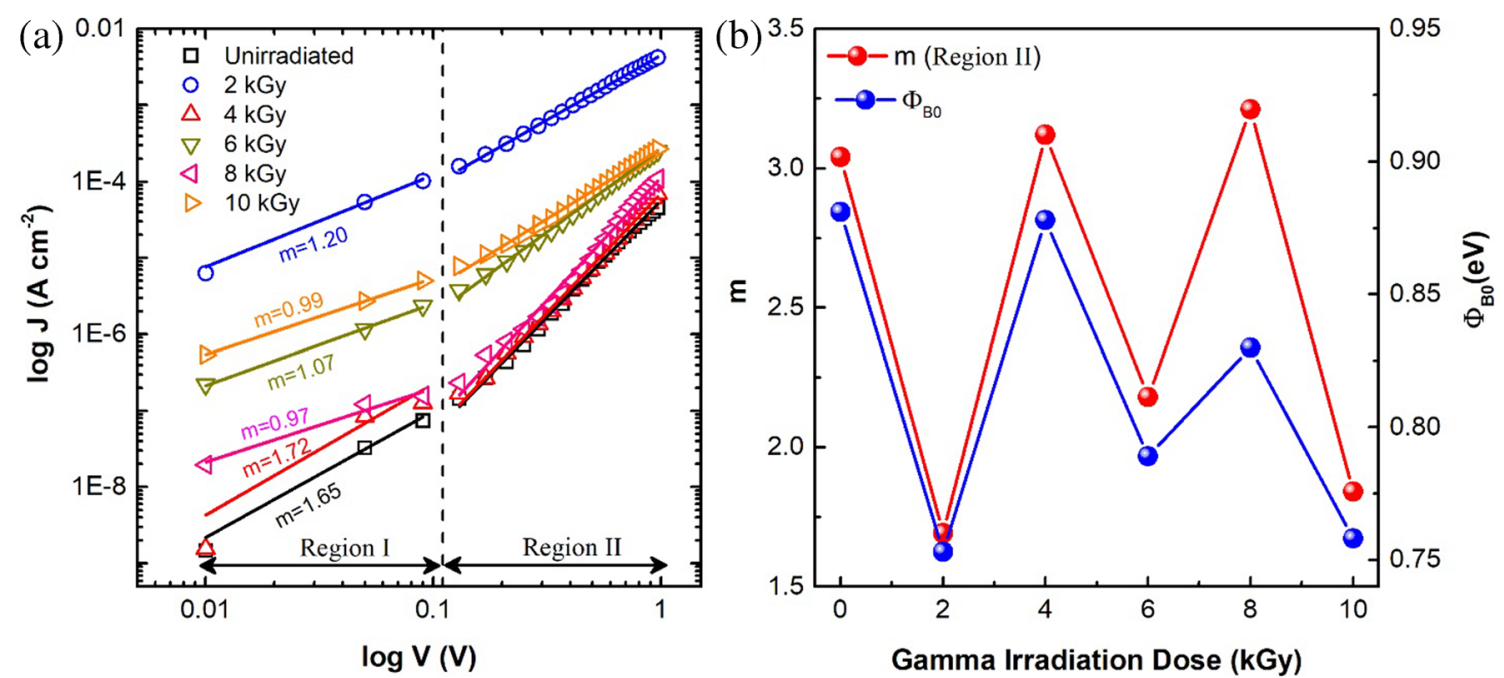

Fig. 8 (a) $\log \mathrm{I}-\log \mathrm{V}$ plots (b) variation of slope parameter $m$ in the region 2 and Schottky barrier height of $n-Z n S e / n-S i$ IHJs at different gamma irradiation doses 
From the above, it is clear that the SCLC mechanism modulated by defects states is dominating over TE mechanism in the $n-\mathrm{ZnSe} / n-\mathrm{Si}$ IHJs over the measured voltage region. It is therefore important to correlate the junction parameters of both the conduction mechanisms. In literature the plots of $m$ (an indication of defect concentration [29]) and $\Phi_{B 0}$ were plotted against radiation doses to correlate them [24]. Figure 8(b) shows the variation of slope $m$ in Region II and $\Phi_{B 0}$ before and after GI. One can notice a definite but linear trend in the correlation between $m$ and $\Phi_{B 0}$ at different GI doses. Here $m$ represents the interface trap concentration. Thus, one can interpret these modified features as real consequences due to defects and their modification at different GI doses. It can be concluded that these defects whether intrinsic or irradiation induced are responsible for poor rectification properties of $n-\mathrm{ZnSe} / n-\mathrm{Si}$ IHJs. However, one must note that the above conclusions are applicable only for polycrystalline $n-\mathrm{ZnSe} / n-\mathrm{Si}$ and cannot be generalized for single crystalline $\mathrm{ZnSe} / \mathrm{Si}$ IHJs. In fact, in the latter case one may anticipate substantial improvements in the ideality factor and better rectification properties for device applications. Also, the degree of radiation induced modifications on the junction properties may remarkably vary.

\section{Conclusions}

A high purity $\mathrm{ZnSe}$ thin film was deposited onto the $n$ $-S i$ substrate by thermal evaporation technique. The XRD studies revealed the nanocrystalline nature of the deposited $\mathrm{ZnSe}$ thin films with prominent (111) orientations. The Co-60 gamma irradiation (GI) at different irradiation doses have shown no crystallographic phase transformations up to the GI dose of $10 k G y$. However, noticeable and inconsistent variations in the $\mathrm{ZnSe}$ lattice parameters such as lattice constant $(a)$, crystallinity (D ) , lattice strain $(\epsilon)$, dislocation density $(\delta)$ and lattice mismatch ( ) were observed at different GI doses due to gamma induced structural modifications by generating defects. The analysis of $I-V$ characteristics of $n-Z n$ $\mathrm{Se} / n-\mathrm{Si}$ isotype heterojunctions (IHJs) revealed that Schottky barrier height $\left(\Phi_{B 0}\right)$ dependence on the type of $S i$ substrate is minimum (within the value of $0.88 \pm 0$ $.10 \mathrm{eV}$ ), but rather depends on the degree of homogeneity of the junction $(\eta)$ due to the differences in the processing conditions, lattice mismatch ( ) and defects. The power law characteristics at different GI doses establishes linear correlation among the junction parameters such as slope parameter $m, \Phi_{B 0}$ and. It is therefore suggested that the poor rectification property of IHJs is essentially contributed by the intrinsic and gammainduced defects and their significant role in the SCLC mechanism.
Acknowledgements The authors are grateful to Manipal Academy of Higher Education and Manipal Institute of Technology. Manipal for providing experimental facility.

Author contributions Conceptualization: Indudhar Panduranga Vali, Rashmitha Keshav, M Rajeshwari, K S Vaishnavi.

Methodology: Indudhar Panduranga Vali, Rashmitha Keshav, M Rajeshwari, K S Vaishnavi.

Formal analysis and investigation: Indudhar Panduranga Vali, Rashmitha Keshav, M Rajeshwari, K S Vaishnavi.

Writing - original draft preparation: Indudhar Panduranga Vali, Rashmitha Keshav, M Rajeshwari, K S Vaishnavi.

Writing - review and editing: M G Mahesha, Pramoda Kumara Shetty. Resources: M G Mahesha, Pramoda Kumara Shetty.

Supervision: M G Mahesha, Pramoda Kumara Shetty.

Funding Open access funding provided by Manipal Academy of Higher Education, Manipal.

Data Availability Data will be made on request.

Code Availability Not applicable.

\section{Declarations}

Conflicts of Interest/Competing Interests The authors declare that they have no known competing financial interests or personal relationships that could have appeared to influence the work reported in this paper.

Ethics Approval Not applicable.

Consent to Participate Not applicable.

Consent for Publication Not applicable.

Open Access This article is licensed under a Creative Commons Attribution 4.0 International License, which permits use, sharing, adaptation, distribution and reproduction in any medium or format, as long as you give appropriate credit to the original author(s) and the source, provide a link to the Creative Commons licence, and indicate if changes were made. The images or other third party material in this article are included in the article's Creative Commons licence, unless indicated otherwise in a credit line to the material. If material is not included in the article's Creative Commons licence and your intended use is not permitted by statutory regulation or exceeds the permitted use, you will need to obtain permission directly from the copyright holder. To view a copy of this licence, visit http://creativecommons.org/licenses/by/4.0/.

\section{References}

1. Milnes AG (1986) Semiconductor heterojunction topics: introduction and overview. Solid- State Electron 29:99-121

2. Chandan G, Mukundan S, Mohan L, Roul B, Krupanidhi SB (2015) Trap modulated photoresponse of InGaN/Si isotype heterojunction at zero-bias. J Appl Phys 118:024503

3. Peibst R, Rugeramigabo EP, Hofmann KR (2012) Electrical characterization and modelling of $\mathrm{n}-\mathrm{nGe}-\mathrm{Si}$ heterojunctions with relatively low interface state densities. J Appl Phys 112:124502

4. Wang P, Jin C, Wu X, Zhan H, Zhou Y, Wang H, Kang J (2012) Quality improvement of $\mathrm{ZnO}$ thin layers overgrown on $\mathrm{Si}(100)$ 
substrates at room temperature by nitridation pretreatment. AIP Adv 2:022139

5. Yawata S, Anderson RL (1965) Optical modulation of current in Ge-Si n-n heterojunctions. Phys Status Solidi B 12:297-304

6. Kim HY, Kim JH, Kim YJ, Chae KH, Whang CN, Song JH, Im S (2001) Photoresponse of Si Detector based on n-ZnO/p-Si and n$\mathrm{ZnO} / \mathrm{n}$-Si structures. Opt Mater 17:141-144

7. Tan ST, Sun XW, Zhao JL, Iwan S, Cen ZH, Chen TP, Ye JD, Lo GQ, Kwong DL, Teo KL (2008) Ultraviolet and visible electroluminescence from $\mathrm{n}-\mathrm{Zn} \mathrm{O}$ Si O x (n, p) - Si heterostructured light-emitting diodes. Appl Phys Lett 93:013506

8. Jeon H, Ding J, Nurmikko AV, Xie W, Grillo DC, Kobayashi M, Gunshor RL, Hua GC, Otsuka N (1992) Blue and green diode lasers in ZnSe-based quantum wells. Appl Phys Lett 60:2045-2047

9. Parent DW, Rodriguez A, Ayers JE, Jain FC (2003)Photo-assisted MOVPE grown (n) $\mathrm{ZnSe} /(\mathrm{p}+) \mathrm{GaAs}$ heterojunction solar cells. Solid-State Electron 47(4):595-599

10. Kühnelt M, Leichtner T, Kaiser S, Hahn B, Wagner HP, Eisert D, Bacher G, Forchel A (1998) Quasiphase matched second harmonic generation in $\mathrm{ZnSe}$ waveguide structures modulated by focused ion beam implantation. Appl Phys Lett 73:584-586

11. Kim BG, Garmire E, Shibata N, Zembutsu S (1987) Optical bistability and nonlinear switching due to increasing absorption in single-crystal ZnSe waveguides. Appl Phys Lett 51(7):475-477

12. Kulp BA, Detweiler RM (1963) Threshold for electron radiation damage in ZnSe. Phys Rev 129:2422-2424

13. Vali IP, Shetty PK, Mahesha MG, Keshav R, Sathe VG, Phase DM, Choudhary RJ (2018) Gamma irradiation effects on Al/n-Si Schottky junction properties. Nuclear Inst Methods in Physics Research B 436:191-197

14. Keshav R, Vali IP, Shetty PK, Vaishnavi KS, Rajeshwari M, Mahesha MG (2020) I - V characterization of vacuum deposited zinc selenide - silicon hetero junction. Indian J Pure Appl Phys 58: $841-846$

15. Güllü HH, Isik M, Gasanly NM, Parlak M (2020) Influence of temperature on optical properties of electron-beam-evaporated ZnSe thin film. Phys Scr 95:075804

16. Güllü HH, Bayraklı Ö, Yildiz DE, Parlak M (2017) Study on the electrical properties of $\mathrm{ZnSe} / \mathrm{Si}$ heterojunction diode. J Mater Sci: Mater Electron 28:17806-17815

17. Venkatachalam S, Mangalaraj D, Narayandass Sa K, Velumani S, Schabes-Retchkiman P, Ascencio JA (2007) Structural studies on vacuum evaporated $\mathrm{ZnSe} / \mathrm{p}-\mathrm{Si}$ Schottky diodes. Mater Chem Phys 103:305-311
18. Wongcharoen N, Gaewdang T (2018) Electrical properties of nanostructure $\mathrm{n}-\mathrm{ZnSe} / \mathrm{p}-\mathrm{Si}(100)$ heterojunction thin film diode. Key Eng Mater 775:246-253

19. Venkatachalam S, Mangalaraj D, Narayandass Sa K (2006) Influence of substrate temperature on the structural, optical and electrical properties of zinc selenide ( $\mathrm{ZnSe}$ ) thin films. J Phys D: Appl Phys 39:4777-4782

20. Venkatachalam S, Kanno Y, Mangalaraj D, Narayandass Sa K (2007) Effect of boron ion implantation on the structural, optical and electrical properties of ZnSe thin films. Phys B 390:71-78

21. Sze SM (1981) Physics of semiconductor devices. Wiley, New York

22. Rhoderick EH, Williams RH (1988)Metal-semiconductor contacts. OxfordScience Publication, Oxford

23. Cheung SK, Cheung NW (1986) Extraction of Schottky diode parameters from forward current-voltage characteristics. Appl Phys Lett 49:85-87

24. Vali IP, Shetty PK, Mahesha MG, Petwal VC, Dwivedi J, Phase DM, Choudhary RJ (2018) Implications of electron beam irradiation on $\mathrm{Al} / \mathrm{n}-\mathrm{Si}$ Schottky junction properties. Microelectron Reliab 91:179-184

25. Hassun HK, Ali HM, Hasan SQA, Maki SA (2019) Effect of alumunium on the structural, optical, electrical, and photovoltaic properties of $\mathrm{ZnSe} / \mathrm{n}$-Si heterojunction solar cell. J Eng Appl Sci 14:4773-1779

26. Güzeldir B, Sa glam M, Ates A (2010) Analysis of the electrical characteristics of $\mathrm{Zn} / \mathrm{ZnSe} / \mathrm{n}-\mathrm{Si} / \mathrm{Au}-\mathrm{Sb}$ structure fabricated using SILAR method as a function of temperature. J Alloys Compd 506:388-394

27. Vali IP, Shetty PK, Mahesha MG, Petwal VC, Dwivedi J, Phase DM, Choudhary RJ (2020) Electron and gamma irradiation effects on $\mathrm{Al} / \mathrm{n}-4 \mathrm{H}-\mathrm{SiC}$ Schottky contacts. Vacuum 172:109068

28. Tung RT (2001) Recent advances in Schottky barrier concepts. Mater Sci Eng RRep 35:1-138

29. Röhr JA, Moia D, Haque SA, Kirchartz T, Nelson J (2018) Exploring the validity and limitations of the Mott-Gurney law for charge-carrier mobility determination of semiconducting thinfilms. J Phys: Condens Matter 30:105901

Publisher's Note Springer Nature remains neutral with regard to jurisdictional claims in published maps and institutional affiliations. 